\title{
Magnetic Activated Carbon Derived from Biomass Waste by Concurrent Synthesis: Efficient Adsorbent for Toxic Dyes
}

André L. Cazetta, ${ }^{\dagger}$ Osvaldo Pezoti, ${ }^{\dagger}$ Karen C. Bedin, ${ }^{\dagger}$ Taís L. Silva, ${ }^{\dagger}$ Andrea Paesano Junior, ${ }^{\S}$ Tewodros Asefa, ${ }^{*, \#, *}$ and Vitor C. Almeida ${ }^{\dagger *} *$

${ }^{\dagger}$ Laboratory of Environmental and Agrochemistry, Department of Chemistry, Universidade Estadual de Maringá, Av. Colombo 5790, Maringá, Paraná, Brazil.

${ }^{\S}$ Department of Physics, Universidade Estadual de Maringá, Av. Colombo, 5790 Maringá, Paraná, Brazil.

$¥$ Department of Chemistry and Chemical Biology, Rutgers, The State University of New Jersey, 610 Taylor Road, Piscataway, New Jersey 08854, USA.

\# Department of Chemical and Biochemical Engineering, Rutgers, The State University of New Jersey, 98 Brett Road, Piscataway, New Jersey 08854, USA.

*Corresponding Author E-mails: (T.A.) tasefa@rci.rutgers.edu; (V.C.A.) vcalmeida@uem.br 
Table S1. Non-linear kinetic models of pseudo-first order, pseudo-second order and Elovich.

Model

Pseudo-first order

Pseudo-second order
Equation

$$
\begin{gathered}
\mathrm{q}_{\mathrm{t}}=\mathrm{q}_{\mathrm{e}}\left[1-\mathrm{e}^{-k_{1} \mathrm{t}}\right] \\
\mathrm{h}_{\mathrm{o}}=k_{1} \mathrm{q}_{\mathrm{e}} \\
\mathrm{q}_{\mathrm{t}}=\frac{k_{2} \mathrm{qe}^{2} \mathrm{t}}{1+k_{2} \mathrm{q}_{\mathrm{e}} \mathrm{t}} \\
\mathrm{h}_{\mathrm{o}}=k_{2} \mathrm{q}^{2} \\
\mathrm{q}_{\mathrm{t}}=\frac{1}{\beta} \ln (1+\alpha \beta \mathrm{t})
\end{gathered}
$$

$k_{l}$ and $k_{2}$ are pseudo-first and pseudo-second order constants, respectively; $h_{o}$ is initial adsorption rate; $\alpha$ and $\beta$ are constants of Elovich model.

\section{Table S2. Non-linear forms of the isotherm models of Langmuir, Freundlich e Dubinin- Radushkevich and thermodynamic equations.}

Isotherm models

Langmuir

Freundlich

Dubinin-Radushkevich

\section{Equation}

$$
\mathrm{q}_{\mathrm{e}}=\frac{\mathrm{Q}_{\mathrm{m}} K_{a} \mathrm{C}_{\mathrm{e}}}{1+K_{a} \mathrm{C}_{\mathrm{e}}}
$$

$$
\mathrm{R}_{\mathrm{L}}=\frac{1}{1+K_{a} \mathrm{C}_{\mathrm{o}}}
$$

$$
\mathrm{q}_{\mathrm{e}}=K_{F} \mathrm{C}_{\mathrm{e}}^{1 / n_{F}}
$$$$
\mathrm{Q}_{\mathrm{e}}=\mathrm{Q}_{\mathrm{m}} \exp \left(-K_{D R}\left[\mathrm{RT} \ln \left(1+\frac{1}{\mathrm{C}_{\mathrm{e}}}\right)\right]^{2}\right)
$$

$$
\mathrm{E}=\frac{1}{\sqrt{2 K_{D R}}}
$$

$$
\begin{array}{cc}
\Delta \mathrm{G}^{\circ}=\Delta \mathrm{H}^{\circ}-\mathrm{T} \Delta \mathrm{S}^{\circ} & \Delta \mathrm{G}^{\circ}=-\mathrm{RT}^{\circ} \mathrm{K}_{\mathrm{e}} \\
\ln \mathrm{K}_{\mathrm{e}}=\frac{\Delta \mathrm{S}^{\circ}}{\mathrm{R}}-\frac{\Delta \mathrm{H}^{\circ}}{\mathrm{R}} \frac{1}{\mathrm{~T}} & \mathrm{~K}_{\mathrm{e}}=\frac{\mathrm{q}_{\mathrm{e}}}{\mathrm{C}_{\mathrm{e}}}
\end{array}
$$

$Q_{m}$ is the maximum adsorption capacity; $K_{a}$ is Langmuir constant; $R_{L}$ is the separation factor; $K_{F}$ and $n_{F}$ are Freundlich constants; $K_{D R}$ is Dubinin-Radushkevich constants; $R$ is the universal gas constant $\left(8.314 \mathrm{~J} \mathrm{~mol}^{-1} \mathrm{~K}^{-1}\right) ; T$ is the absolute temperature in Kelvin $(298 \mathrm{~K})$ and $E$ is the adsorption energy $(\mathrm{kJ}) . \Delta \mathrm{G}^{\mathrm{o}}$ is the change in Gibb's free energy, $\Delta \mathrm{S}^{\mathrm{o}}$ is the change in entropy, $\Delta \mathrm{H}^{\mathrm{o}}$ is the change in enthalpy, $\mathrm{R}$ is the gas constant $(8.314 \mathrm{~J} / \mathrm{mol} / \mathrm{K}), \mathrm{K}_{\mathrm{e}}$ is the dimensional equilibrium constant $\left(\mathrm{g} \mathrm{L}^{-1}\right)$. 
Table S3. Relative elementary composition by XPS.

\begin{tabular}{cccc} 
Element & MAC1 (\%) & MAC2 $(\%)$ & MAC3 (\%) \\
$\mathrm{C}$ & 86.40 & 72.74 & 64.39 \\
$\mathrm{O}$ & 11.63 & 23.12 & 29.23 \\
$\mathrm{Fe}$ & 1.17 & 2.91 & 4.93 \\
$\mathrm{~N}$ & 0.80 & 1.23 & 1.45 \\
\hline
\end{tabular}

\begin{tabular}{|c|c|c|c|}
\hline Temperature (K) & $\Delta \mathrm{G}^{\mathrm{o}}\left(\mathrm{kJ} \mathrm{mol}^{-1}\right)$ & $\Delta \mathrm{H}^{\mathrm{o}}\left(\mathrm{kJ} \mathrm{mol}^{-1}\right)$ & $\Delta \mathrm{S}^{\mathrm{o}}\left(\mathrm{J} \mathrm{mol}^{-1} \mathrm{~K}^{-1}\right)$ \\
\hline 308 & -2.84 & \multirow{3}{*}{52.57} & \multirow{3}{*}{195.71} \\
\hline 318 & -4.36 & & \\
\hline 328 & -6.85 & & \\
\hline
\end{tabular}<smiles>O=S(=O)(O[Na])c1ccc(/N=N/c2c(O)ccc3cc(S(=O)(=O)O[Na])ccc23)cc1</smiles>

Figure S1. Chemical structure of Sunset Yellow food dye (SY). 

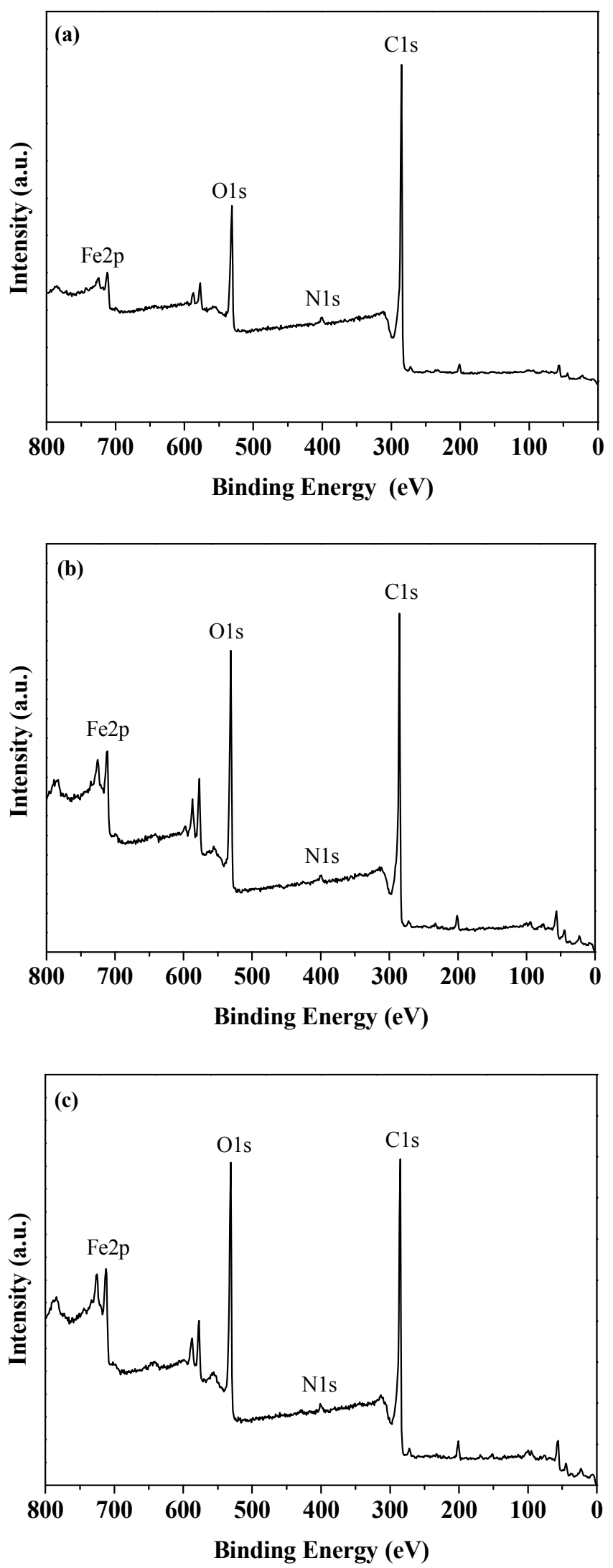

Figure S2. XPS survey spectra for different materials: MAC1 (a), MAC2 (b) and MAC3 (c). 

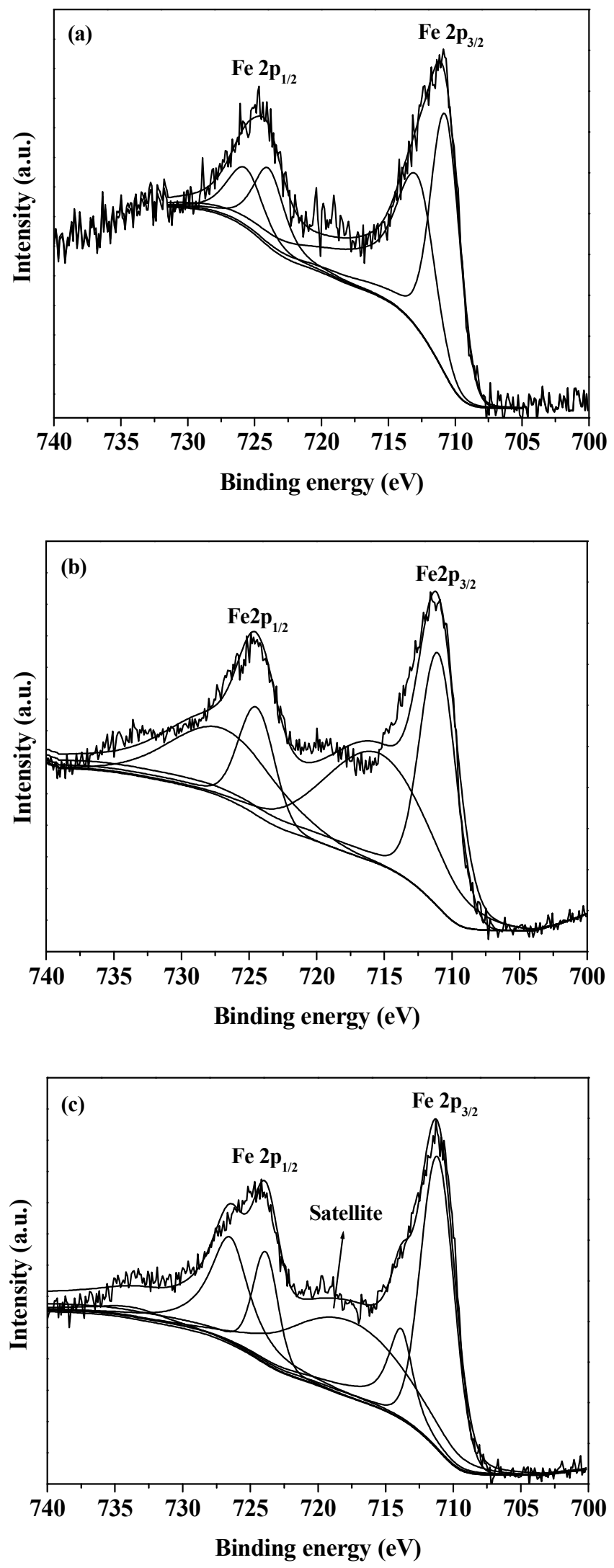

Figure S3. Deconvoluted XPS spectra of Fe2p peak of MAC1 (a), MAC2 (b) and MAC3 (c). 

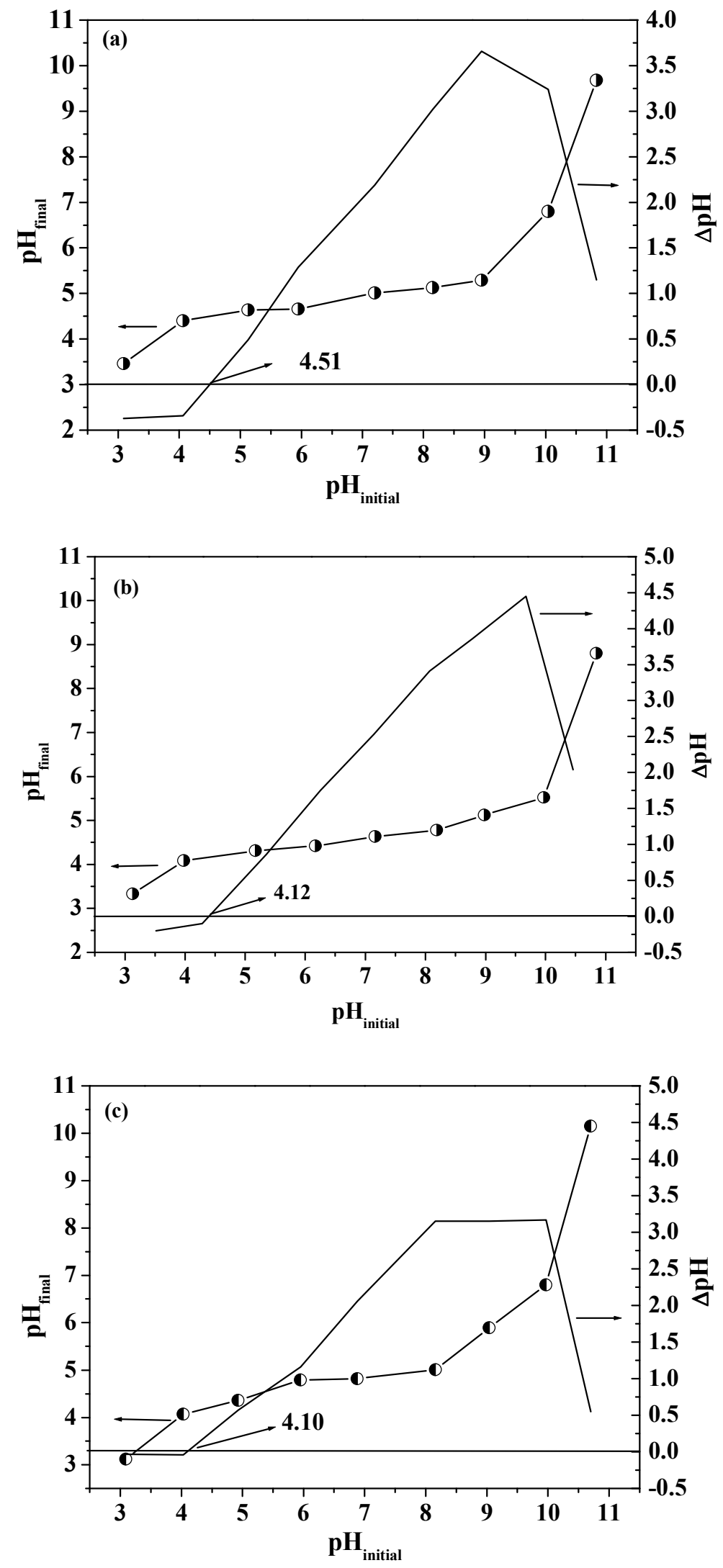

Figure S4. $p H_{p z c}$ of the MAC1 (a), MAC2 (b) and MAC3 (c). 


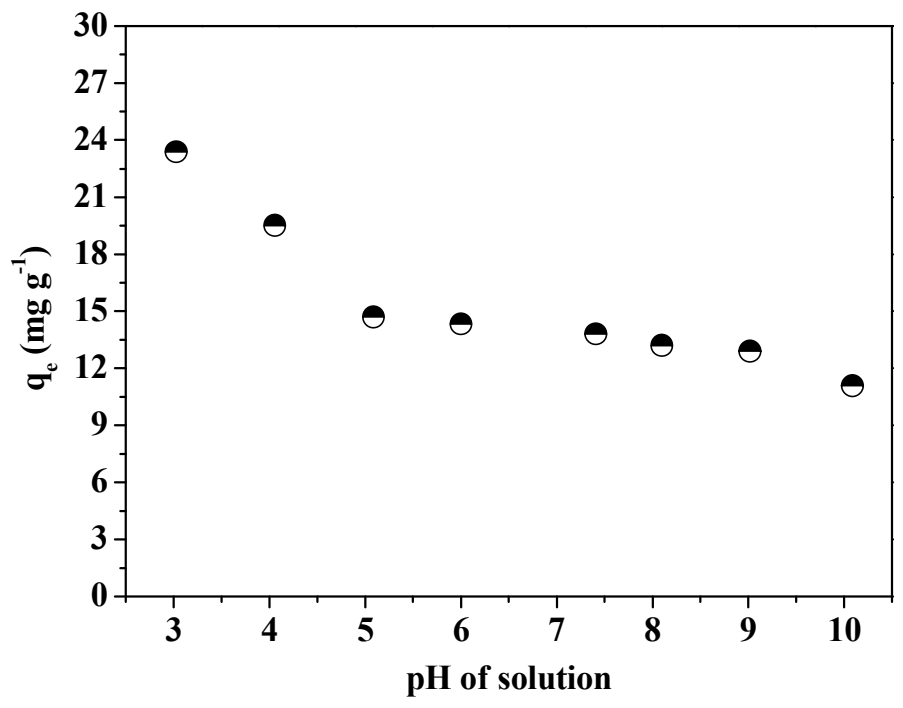

Figure S5. Effect of initial pH in the adsorption of SY on MAC1.

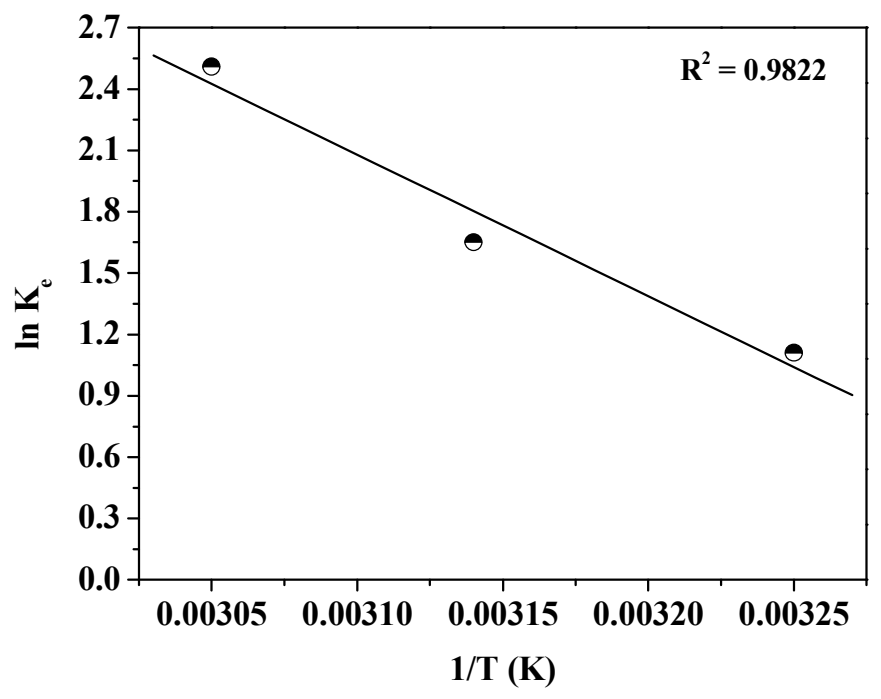

Figure S6. Results of thermodynamic analyses (ln $\mathrm{K}_{\mathrm{e}}$ versus $1 / \mathrm{T}$ ) for the adsorption of SY on a MAC material. 